\title{
A model of clinical endometritis in Holstein heifers using pathogenic Escherichia coli and Trueperella pyogenes
}

\author{
Rachel L. Piersanti, ${ }^{1}$ Roney Zimpel, ${ }^{1}$ Paula C. C. Molinari, ${ }^{1}$ Mackenzie J. Dickson, ${ }^{1}$ Zhengxin Ma, ${ }^{1}$ \\ KwangCheol C. Jeong, ${ }^{1}$ José E. P. Santos, ${ }^{1}$ I. Martin Sheldon, ${ }^{2}$ and John J. Bromfield ${ }^{1 *}$ \\ ${ }^{1}$ Department of Animal Sciences, University of Florida, Gainesville 32611 \\ ${ }^{2}$ Institute of Life Science, Swansea University Medical School, Swansea, SA2 8PP, United Kingdom
}

\section{ABSTRACT}

Bacterial infection of the uterus causes clinical endometritis in 15 to $20 \%$ of postpartum dairy cows and reduces fertility, even after the resolution of disease. However, it is difficult to disentangle the mechanisms linking reduced fertility with endometritis because cows have multiple confounding postpartum conditions. The aim of the present experiment was to develop an in vivo model of clinical endometritis in Holstein heifers using pathogenic Escherichia coli and Trueperella pyogenes. Estrous cycles of heifers were synchronized using a 5-d Co-Synch protocol, and subsequently received exogenous progesterone to elevate circulating progesterone at the time of uterine infusion. Endometrial scarification was performed before uterine infusion of live pathogenic Escherichia coli and Trueperella pyogenes, or sterile vehicle. Effects of infusion were evaluated by measuring rectal temperature, plasma haptoglobin, hematology, grading pus in the vaginal mucus, quantifying $16 \mathrm{~S}$ rRNA in vaginal mucus, and transrectal ultrasonography. Bacterial infusion increased the median vaginal mucus to grade 2 by d 3 postinfusion, and to grade 3 from d 4 to 6 postinfusion. Control heifers maintained a median vaginal mucus grade $\leq 1$ from $d$ 1 to 6 . Transrectal ultrasound revealed the accumulation of echogenic fluid in the uterus of heifers following bacterial infusion, which was absent in control heifers. Total 16S rRNA in vaginal mucus was elevated in bacteria-infused heifers compared with control heifers at $\mathrm{d} 5$. Rectal temperature was increased in bacteriainfused heifers. Plasma haptoglobin, general health, and appetite did not differ between groups. As indicated by increased vaginal mucus grade after bacterial infusion and absence of systemic signs of illness, this model successfully induced symptoms resembling clinical endometritis in virgin Holstein heifers. The model

Received August 24, 2018.

Accepted December 4, 2018.

*Corresponding author: jbromfield@ufl.edu allows the isolation of effects of uterine disease on fertility from confounding factors that can occur during the postpartum period in dairy cows.

Key words: animal model, dairy cow, clinical endometritis, inflammation, uterine infection

\section{INTRODUCTION}

Clinical endometritis is characterized by inflammation resulting from bacterial infection of the endometrium that causes a purulent uterine discharge that is present $21 \mathrm{~d}$ or more postpartum. Endometritis has a lactation incidence of 15 to $20 \%$ and is important because, even after resolution of the clinical signs, cows have delayed conception and are more likely to be culled for reproductive failure than cows without endometritis (LeBlanc et al., 2002; Gernand et al., 2012; Ribeiro et al., 2013). However, understanding how uterine disease affects fertility is complicated because endometritis is associated with other peripartum problems as well as metabolic challenges associated with the onset of lactation, which also impair fertility (LeBlanc, 2012; Ribeiro et al., 2013). Developing an experimental model of clinical endometritis in heifers would help disentangle the mechanisms of how uterine disease affects reproductive physiology.

Cows with clinical endometritis do not have systemic signs of disease, and diagnosis is based on the presence of a purulent uterine discharge detectable in the vagina $21 \mathrm{~d}$ or more postpartum (LeBlanc et al., 2002; Sheldon et al., 2006). The vaginal contents can be examined using a gloved hand, a Metricheck tool (Simcro, Hamilton, New Zealand), or a speculum, and the severity of clinical endometritis can be graded by the amount of pus in the mucus. There is debate about whether purulent vaginal discharge may also reflect cervicitis or vaginitis because not all cows with purulent vaginal discharge have infiltration of polymorphonuclear neutrophils detectable by endometrial cytology (Dubuc et al., 2010). Nevertheless, bacteria can be isolated from the uterus of cows with endometritis, and the presence 
of pus in the uterus or a slightly enlarged uterus can also be visualized using transrectal ultrasonography (Sheldon et al., 2002).

Clinical endometritis is associated with gram-negative endometrial pathogenic Escherichia coli, grampositive Trueperella pyogenes, and several anaerobes (Sheldon et al., 2002; Bicalho et al., 2012). Both E. coli and T. pyogenes can be detected in the uterus of cows that develop uterine disease as early as 1 to 3 DIM based on culture and PCR-based technologies (Dohmen et al., 2000; Bicalho et al., 2012). Lipopolysaccharide from gram-negative bacteria and lipopeptides from gram-positive bacteria activate the innate immune system in the endometrium, leading to inflammation and increased concentrations of circulating acute phase proteins (Sheldon et al., 2001; LeBlanc, 2012; Turner et al., 2014). Pus forms in the uterus when neutrophils phagocytize bacteria or endometrial cells damaged by cytolysins, such as the pore-forming toxin pyolysin secreted by T. pyogenes (Sheldon et al., 2010; Bicalho et al., 2012; Amos et al., 2014). A notable feature of the pathogenesis of endometritis is that the adhesion of $E$. coli to endometrial cells and the cytolysis caused by pyolysin is greatest in the stroma, which is exposed when the epithelium is lost during the peripartum period (Sheldon et al., 2010; Amos et al., 2014). Furthermore, peripartum problems that traumatize the endometrium, such as dystocia and retained fetal membranes, increase the risk of development of endometritis (Dubuc et al., 2010; Potter et al., 2010; Ribeiro et al., 2013).

Uterine disease is associated with prolonged luteal phases, slowed rate of growth of ovarian follicles postpartum, and impaired ovarian endocrine function (Opsomer et al., 2000; Sheldon et al., 2002). However, the mechanisms linking endometritis with reproduction are not fully established because fertility is also perturbed by many of the risk factors for endometritis, including peripartum problems and the inability to adapt to the shifts in metabolism to accommodate lactation (Chagas et al., 2007; LeBlanc, 2012). Animal models of clinical endometritis have been reported using mature cows infused with T. pyogenes (Rowson et al., 1953; Ayliffe and Noakes, 1982; Farin et al., 1989; Amos et al., 2014). However, an experimental model of endometritis in heifers would be attractive for exploring how uterine infection affects reproduction. Using heifers as the basis for the model circumvents many of the confounding effects of parturition and lactation observed in lactating cows. The aim of the present experiment was to develop a defined in vivo infection model of clinical endometritis in Holstein heifers using pathogenic E. coli and T. pyogenes.

\section{MATERIALS AND METHODS}

The University of Florida Institutional Animal Care and Use Committee approved all procedures with heifers under protocol number 201508884. The experiment was conducted from June to October 2017 at the University of Florida Dairy Unit.

\section{Establishment of Uterine Infection in Heifers}

Nine virgin Holstein heifers aged between 11 and 13 mo were enrolled in the experiment. All animals were free of general health conditions and tested negative for Brucella abortus, Neospora caninum, and Leptospirosa. Heifers were vaccinated against bovine viral diarrhea, infectious bovine rhinotracheitis, parainfluenza, bovine respiratory syncytial virus, and multiple serovars of Leptospira (Bovi-Shield Gold FP 5 VL5 HB, Zoetis, Parsippany, NJ) and dewormed using moxidectin (Cydectin, Bayer HealthCare LLC, Animal Health Division, Shawnee Mission, KS). Heifers were fed a diet as TMR that was offered once a day in addition to pasture access and provided ad libitum access to water.

The experiment followed a randomized complete block design with heifer as the experimental unit. Heifers were blocked by age and weight, and randomly assigned to 1 of 2 infusion treatments: intrauterine infusion of sterile vehicle medium alone $(\mathrm{n}=5)$ or intrauterine infusion of live bacteria $(\mathrm{n}=4$; details below).

Estrous cycles were synchronized using a modified 5 -d Co-synch protocol (Lima et al., 2013). Briefly, heifers received $100 \mathrm{mg}$ i.m. of $\mathrm{GnRH}$ (gonadorelin diacetate tetrahydrate; Ovacyst, Bayer) followed by $25 \mathrm{mg}$ i.m. of $\mathrm{PGF}_{2 \alpha}$ (dinoprost tromethamine; Prostamate, Bayer) administered 5 and 6 d later (Figure 1A). Eight days following initial $\mathrm{GnRH}$, heifers received a final dose of $100 \mathrm{mg}$ of GnRH i.m. Starting on the day following the final $\mathrm{GnRH}$, heifers received $200 \mathrm{mg}$ i.m. of progesterone (P4) in corn oil $(50 \mathrm{mg} / \mathrm{mL}$; Sigma-Aldrich, St Louis MO) daily for $7 \mathrm{~d}$. Exogenous P4 was administered to mimic diestrus and ensure elevated circulating $\mathrm{P} 4$ at the time of bacterial infusion.

Uterine infusion of treatments were performed $72 \mathrm{~h}$ following final $\mathrm{GnRH}$ administration and designated as d 0 relative to treatment (Figure 1A). Endometrial scarification was implemented before intrauterine infusion to disrupt the endometrial epithelium. Heifers were restrained and received a caudal epidural injection of $60 \mathrm{mg}$ of lidocaine hydrochloride 2\% (Aspen Veterinary Resources, Greeley, CO). The perineum and vulva were cleaned and disinfected with povidone iodine followed by $70 \%$ ethanol, and a sterile metal scarification tool enclosed by a metal catheter covered in a sanitary sheath 

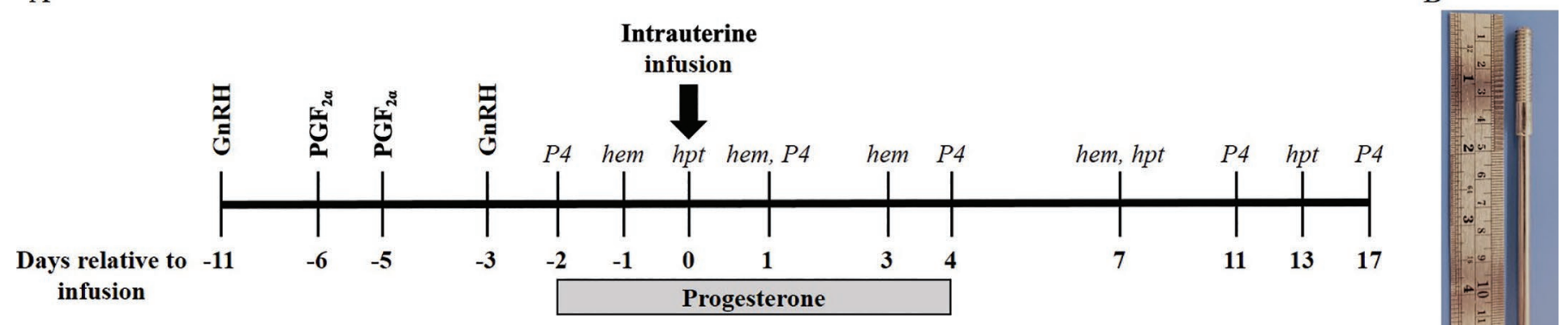

Figure 1. Requirements for establishment of experimental uterine infection. (A) Timeline of experimental procedures employed during the experimental period. Gonadotropin-releasing hormone and $\mathrm{PGF}_{2 \alpha}$ were used to synchronize estrous cycles in 9 virgin Holstein heifers before intrauterine infusion of treatments. On d 0, intrauterine infusion of either vehicle or live bacteria was performed. Vehicle infusion consisted of 30 $\mathrm{mL}$ of sterile Luria-Bertani broth. Bacteria infusion consisted of $10 \mathrm{~mL}$ of Escherichia coli MS $499\left(4.64 \times 10^{7} \mathrm{cfu} / \mathrm{mL}\right), 10 \mathrm{~mL}$ of Trueperella pyogenes MS249 $\left(3.38 \times 10^{7} \mathrm{cfu} / \mathrm{mL}\right)$, and $10 \mathrm{~mL}$ of sterile Luria-Bertani broth. Progesterone (P4) was administered at $200 \mathrm{mg} / \mathrm{d}$ i.m. Days relative to treatment for evaluation of plasma haptoglobin $(h p t), \mathrm{P} 4(P 4)$, and hematology $(h e m)$ are indicated in italics. (B) The tool used to enable scarification of the endometrium.

(IMV Technologies, Normandy, France) was introduced through the vagina and cervix. The scarification tool consisted of a stainless-steel rod with a 39-mm-long, 6-mm-diameter threaded component on the tip, similar to a threaded bolt (Figure 1B). The scarification tool was manipulated through the cervix and into the body of the uterus by transrectal palpation. Once inside the body of the uterus, the sanitary sheath was retracted, and the scarification tool was placed in direct contact with the endometrium. The scarification tool was then rotated once to disrupt the endometrial lining before removal from the reproductive tract. Inspection of the scarification tool upon retraction confirmed tissue disruption by the presence of small pieces of tissue. Following endometrial scarification, a metal infusion catheter enclosed in a sanitary sheath was introduced transcervically into the body of the uterus. The sanitary sheath was retracted, and treatments were infused using 10-mL syringes. Bacterial infusion consisted of $10 \mathrm{~mL}$ of $4.64 \times 10^{7} \mathrm{cfu} / \mathrm{mL}$ of E. coli MS499, $10 \mathrm{~mL}$ of $3.38 \times 10^{7} \mathrm{cfu} / \mathrm{mL}$ T. pyogenes MS249 followed by $10 \mathrm{~mL}$ of sterile Luria-Bertani (LB) broth to flush the catheter (Goldstone et al., 2014a,b). Vehicle infusion consisted of $30 \mathrm{~mL}$ of LB broth. Heifers were returned to pasture and monitored for clinical signs for $24 \mathrm{~h}$.

Animals did not receive any additional treatments or medication during the experimental period.

\section{Bacterial Culture and Preparation of Inoculants}

Escherichia coli MS499 and T. pyogenes MS249 were collected and isolated from cows with metritis and characterized previously (Goldstone et al., 2014a,b).

Escherichia coli was cultured from frozen glycerol stocks on LB agar. The day before infusion, a single colony was picked from the plate and inoculated into
LB broth containing $1 \%$ tryptone, $0.5 \%$ yeast extract, and $1 \%$ sodium chloride. The culture was incubated overnight at $37^{\circ} \mathrm{C}$ with shaking at $200 \mathrm{rpm}$. Growth was monitored by measuring optical density at $600 \mathrm{~nm}$ $\left(\mathrm{OD}_{600}=5.0\right)$. A final preparation of $4.64 \times 10^{7} \mathrm{cfu} / \mathrm{mL}$ E. coli was diluted in sterile LB broth and loaded into 10-mL syringes for infusion.

Trueperella pyogenes MS249 was grown from frozen glycerol stocks on Trypticase Soy Blood agar at $37^{\circ} \mathrm{C}$ for $48 \mathrm{~h}$. The day before infusion, a single colony was selected and inoculated into Bacto Brain Heart Infusion broth (BHI, Fisher Scientific, Pittsburgh, PA) supplemented with $5 \%$ fetal bovine serum (FBS, Fisher Scientific) and cultured overnight at $37^{\circ} \mathrm{C}$ with shaking at $200 \mathrm{rpm}$. Growth was monitored by measuring optical density at $600 \mathrm{~nm}\left(\mathrm{OD}_{600}=0.2\right)$. A final preparation of $3.38 \times 10^{7} \mathrm{cfu} / \mathrm{mL} \mathrm{T}$. pyogenes was diluted in sterile BHI and loaded into 10-mL syringes for infusion. Syringes were loaded with sterile LB broth for flushing catheters and vehicle infusions. Inoculants were transported to the farm on ice for infusion.

\section{Blood Sampling and Hematology}

Blood was collected from the coccygeal vessels into evacuated tubes (Vacutainer, Becton Dickson, Franklin Lakes, NJ) containing sodium heparin for plasma separation or potassium EDTA for hematology. Blood was sampled every other day from d -2 to 18 relative to treatment. Blood was placed on ice until further processing. Tubes containing heparin were centrifuged and plasma was collected, aliquoted, and stored at $-20^{\circ} \mathrm{C}$. Whole blood was transported to the laboratory on ice within $2 \mathrm{~h}$ of collection and used for hematology analysis performed using an automated hematology analyzer (ProCyte Dx Hematology Analyzer, IDEXX Labora- 
tories, Westbrook ME). Hematology analysis included total and differential leukocyte counts (neutrophils, lymphocytes, and eosinophils), red blood cells, hematocrit, and hemoglobin. Hematology was evaluated on d $-1,1,3$, and 7 relative to treatment (Figure 1A).

Plasma haptoglobin (Life Diagnostics Inc., West Chester, PA) and P4 (DRG International Inc., Springfield, NJ) were measured using commercially available ELISA according to the manufacturer's instructions. Plasma haptoglobin was evaluated on d 0,7 , and 13 relative to treatment, and $\mathrm{P} 4$ was evaluated on $\mathrm{d}-2,1$, 4,11 , and 17 relative to treatment (Figure $1 \mathrm{~A}$ ). The $\mathrm{P} 4$ ELISA is human specific and was validated for bovine plasma using spike-in/recovery performance based on actual and expected recovery of P4 supplied as standard with the kit. The intraassay coefficient of variation was calculated at $6.5 \%$, and recovery of spike-in $\mathrm{P} 4$ was 89 to $101.8 \%$ of expected $\mathrm{P} 4$.

\section{Examination and Grading of Vaginal Mucus, Transrectal Ultrasonography, and Rectal Temperature}

Vaginal mucus was collected and examined using a clean Metricheck tool (Simcro). Vaginal mucus was scored as grade 0, no mucus or clear or translucent mucus; grade 1, mucus containing flecks of white or off-white pus; grade 2, mucus containing $\leq 50 \%$ white or off-white mucopurulent material; and grade 3, mucus containing $>50 \%$ purulent material (Sheldon et al., 2009). Evaluation of vaginal mucus was performed daily from $\mathrm{d}-1$ to 7 relative to treatment (Figures $2 \mathrm{~A}-2 \mathrm{C}$ ).

Transrectal ultrasonography with a linear $5.0 \mathrm{MHz}$ probe (Aloka SSD-500, Hitachi Healthcare Americas, Twinsburg, $\mathrm{OH}$ ) was performed to visualize fluid and pus in the uterus. Ultrasonography was performed every other day from $\mathrm{d}-1$ to 10 relative to treatment.
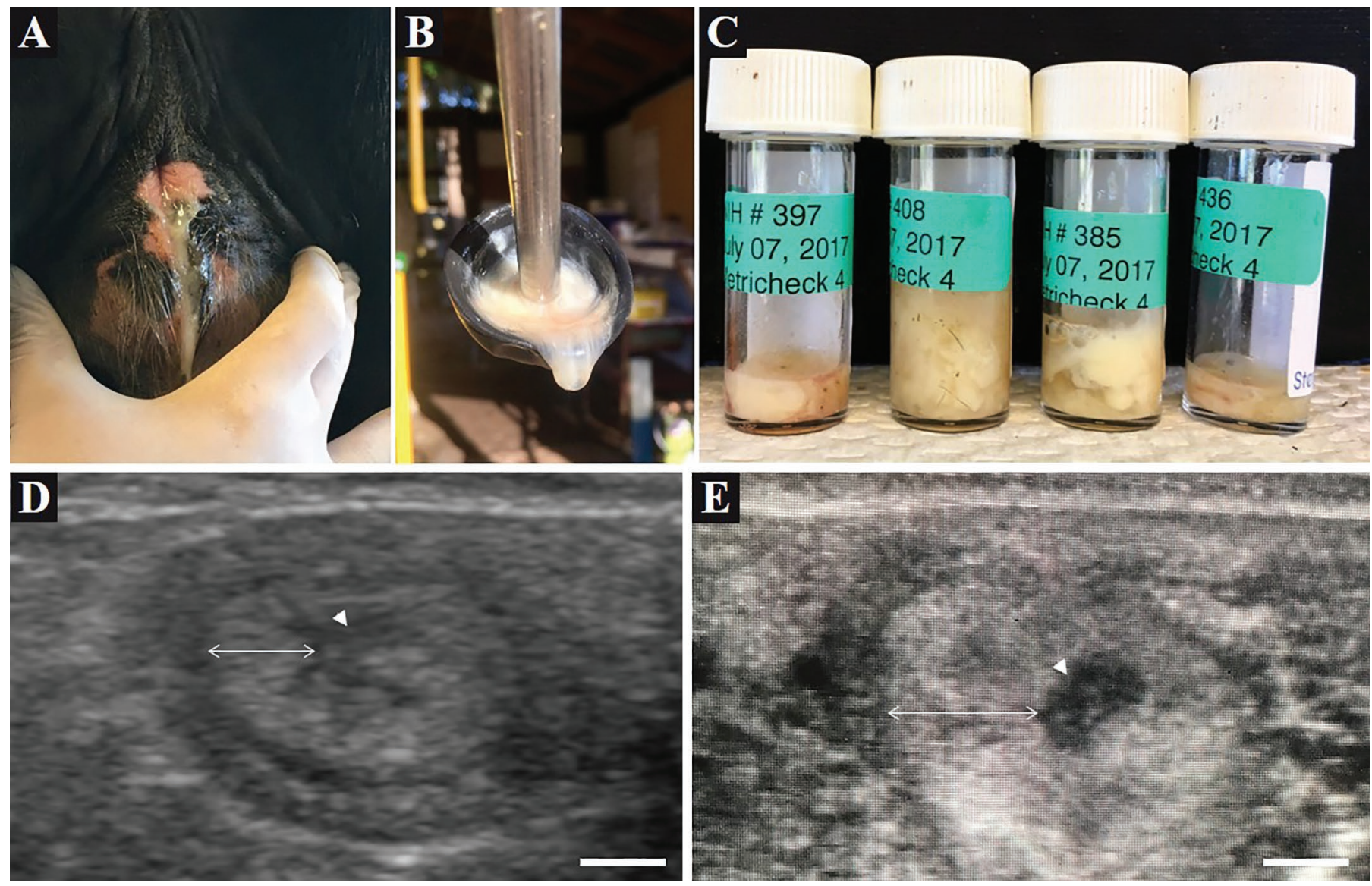

Figure 2. Clinical observations of induced uterine disease. (A) Vaginal mucus was visually confirmed in heifers receiving bacterial infusion. (B) Metricheck (Simcro, Hamilton, New Zealand) tool containing vaginal mucus of a bacteria-infused heifer. (C) Examples of vaginal mucus samples collected from bacteria-infused heifers using the Metricheck tool. (D and E) Representative ultrasound images of a transverse crosssection of a uterine horn from a control (D) and bacteria-infused (E) heifer. The arrow head denotes the uterine lumen; the double-headed arrow denotes the uterine wall. The scale bar represents $5 \mathrm{~mm}$. 
Rectal temperature (AG-102 thermometer, AG-Medix, Mukwonago, WI) was measured daily between 0700 and $0900 \mathrm{~h}$ from $\mathrm{d}-11$ to 10 relative to treatment. A rectal temperature of $>39.5^{\circ} \mathrm{C}$ was classified as fever.

\section{Quantification of Total 16S rRNA Isolated From Vaginal Mucus}

Vaginal mucus was stored in sterile bijou bottles at $-20^{\circ} \mathrm{C}$ until processing. Total DNA was isolated from vaginal mucus using the DNeasy Power Soil Kit according to the manufacturer's instructions with modification (Qiagen, Hilden, Germany). Briefly, samples were thawed on ice and vortexed and $250 \mathrm{mg}$ of vaginal mucus was used for DNA extraction using a bead beater tissue homogenizer (Precellys 24, Bertin Technologies SAS, Montigny-le-Bretonneux, France). The mucus was added to guanidine thiocyanate and homogenized with garnet particles using 3 bead beater cycles (30 $\mathrm{s}$ at $6,000 \times g, 60 \mathrm{~s}$ pause, $30 \mathrm{~s}$ at $6,000 \times g)$ with a 5 min incubation on ice between each cycle. Following homogenization, supernatants were applied to the DNeasy Power Soil spin columns for DNA purification.

Total 16S rRNA was quantified using the Femto Bacterial DNA Quantification Kit according to the manufacturer's instructions (Zymo Research, Irvine, CA). Thermocycling conditions included initial denaturation at $95^{\circ} \mathrm{C}$ for $10 \mathrm{~min}, 40$ cycles of amplification consisting of denaturation at $95^{\circ} \mathrm{C}$ for $30 \mathrm{~s}$, annealing at $50^{\circ} \mathrm{C}$ for $30 \mathrm{~s}$ and extension at $72^{\circ} \mathrm{C}$ for $1 \mathrm{~min}$, followed by a final extension at $72^{\circ} \mathrm{C}$ for $7 \mathrm{~min}$. A total of $2 \mu \mathrm{L}$ of extracted total DNA sample was applied to each PCR reaction. Quantification of $16 \mathrm{~S}$ rRNA was analyzed based on a standard curve performed in parallel with mucus samples. Data for total 16S rRNA are described as nanograms of $16 \mathrm{~S}$ rRNA per milligram of vaginal mucus. The extraction of $16 \mathrm{~S}$ rRNA in mucus samples was validated using spike-in/recovery using known quantities of purified bacteria. Intraassay coefficient of variation was calculated at $0.3 \%$, interassay coefficient of variation was calculated at $2.2 \%$, and recovery of $16 \mathrm{~S}$ rRNA following extraction of bacteria spike-in pus was $100.5 \%$ of expected $16 \mathrm{~S}$ rRNA content.

\section{Statistical Analysis}

All data were analyzed using SAS v. 9.4 (SAS Institute Inc., Cary, NC). Vaginal mucus grade was reported as the median for each treatment group and analyzed using the GLIMMIX procedure following a Poisson distribution. Cow within treatment was considered a random effect, and fixed effects of treatment and day were analyzed. Haptoglobin, P4, hematology, and DNA con- centration for the $16 \mathrm{~S}$ rRNA gene were analyzed using the MIXED procedure of SAS and the models included the fixed effects of treatment (bacterial infusion), day (repeated measure), and their interaction. Heifer nested within treatment was considered as a random effect. First order autoregressive covariance structure AR (1) was used as the covariate structure. Values are reported as least squares means \pm standard error of the mean. Differences with $P \leq 0.05$ were considered statistically significant.

\section{RESULTS}

\section{Intrauterine Bacterial Infusion Increased Vaginal Mucus Grade}

Vaginal discharge of pus was visually evident in heifers that were infused with live bacteria, but not in control heifers (Figure 2A). Vaginal mucus collected by Metricheck was graded and compared between treatments (Figure 2B-2C). An increase $(P<0.02)$ was observed in the vaginal mucus grade of heifers treated with bacteria (Figure 3). Heifers in both infusion groups had a median mucus grade of 0 before uterine infusion (Figure 3). Intrauterine infusion of live bacteria resulted in a median mucus grade of 2 on d 3 relative to treatment, whereas control heifers maintained a median mucus grade of 0 (Figure 3). On d 4 to 6 relative to treatment, bacteria-infused heifers had a median mucus grade of 3 , whereas control heifers presented a median mucus grade $\leq 1$. The presence of echogenic fluid in the uterus of bacteria-infused heifers was confirmed by transrectal ultrasound, and control heifers had no evidence of increased fluid, or echogenic material present in the uterus (Figure 2D-2E).

\section{Intrauterine Bacterial Infusion Increased 16S rRNA Concentration in Vaginal Mucus}

Total vaginal $16 \mathrm{~S}$ rRNA was increased $(P<0.05)$ in bacteria-infused heifers compared with control heifers on d 5 (Figure $4 \mathrm{~A}$ ). In addition, total vaginal $16 \mathrm{~S}$ rRNA was greater $(P<0.05)$ on $\mathrm{d} 5$ in heifers infused with bacteria compared with other sampled days (Figure 4A). No interaction was observed between treatment and day relative to treatment $(P=0.14)$.

\section{Effect of Uterine Bacterial Infusion on Hematology and Rectal Temperature}

Treatment had no effect on any hematological parameters measured (Table 1). Day relative to treatment 
had an effect $(P<0.05)$ on the number of red blood cells $(\mathrm{M} / \mu \mathrm{L})$, number of lymphocytes $(\mathrm{K} / \mu \mathrm{L})$, number of platelets $(\mathrm{K} / \mu \mathrm{L})$, and percent of hematocrit and hemoglobin $(\mathrm{g} / \mathrm{dL})$. A tendency was observed for an effect of treatment $(P=0.08)$ on rectal temperature with bacteria-infused heifers showing elevated temperature on d 1 compared with control heifers (Table 1). Two bacteria-infused heifers had rectal temperatures above $39.5^{\circ} \mathrm{C}$ on $\mathrm{d} 1$ relative to treatment $\left(40.0\right.$ and $\left.40.2^{\circ} \mathrm{C}\right)$. No overt signs of systemic disease were observed in any heifers.

\section{Effect of Bacterial Infusion on Circulating Concentrations of Haptoglobin and Progesterone in Plasma}

Plasma concentration of haptoglobin did not differ $(P=0.70)$ between treatments and there was no effect of day $(P=0.36)$ or interaction between day and treatment $(P=0.41)$. A numerical 3.5 -fold increase in haptoglobin concentration on d 13 relative to treatment was observed in bacteria-infused heifers compared with control heifers (Figure 4B; $P>0.05$ ).

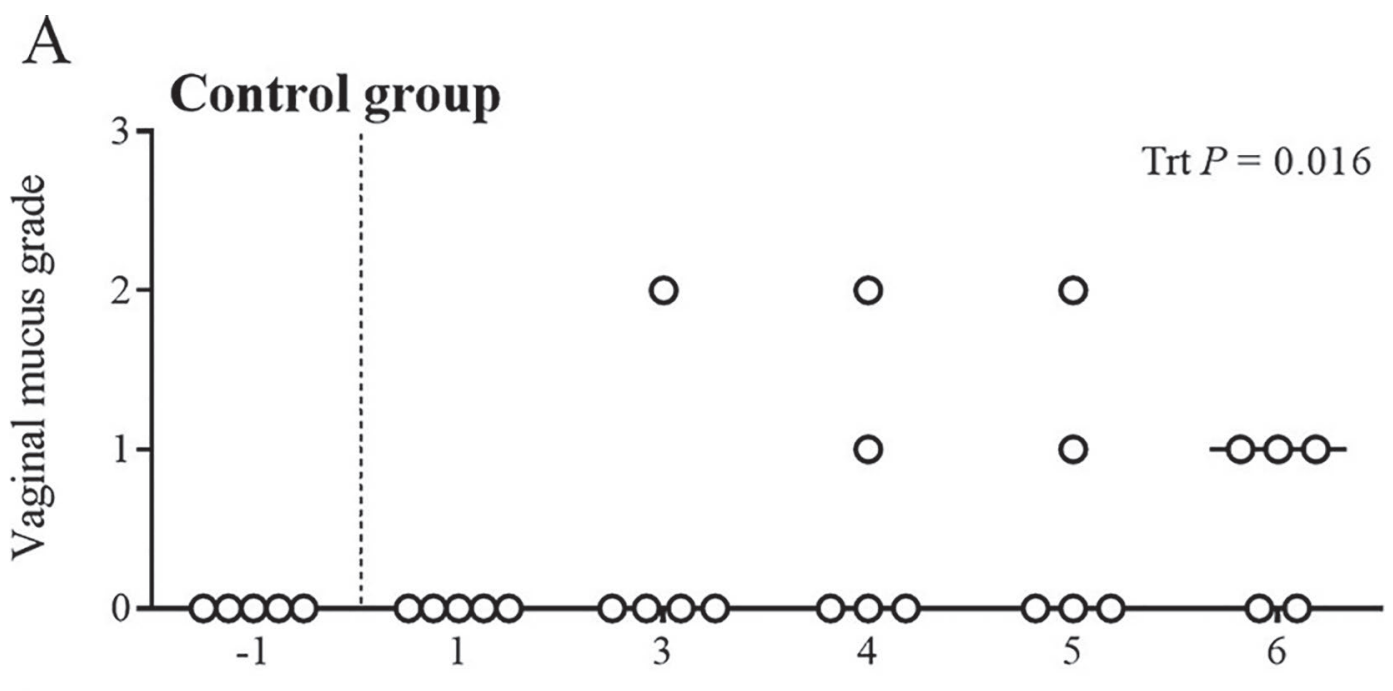

B

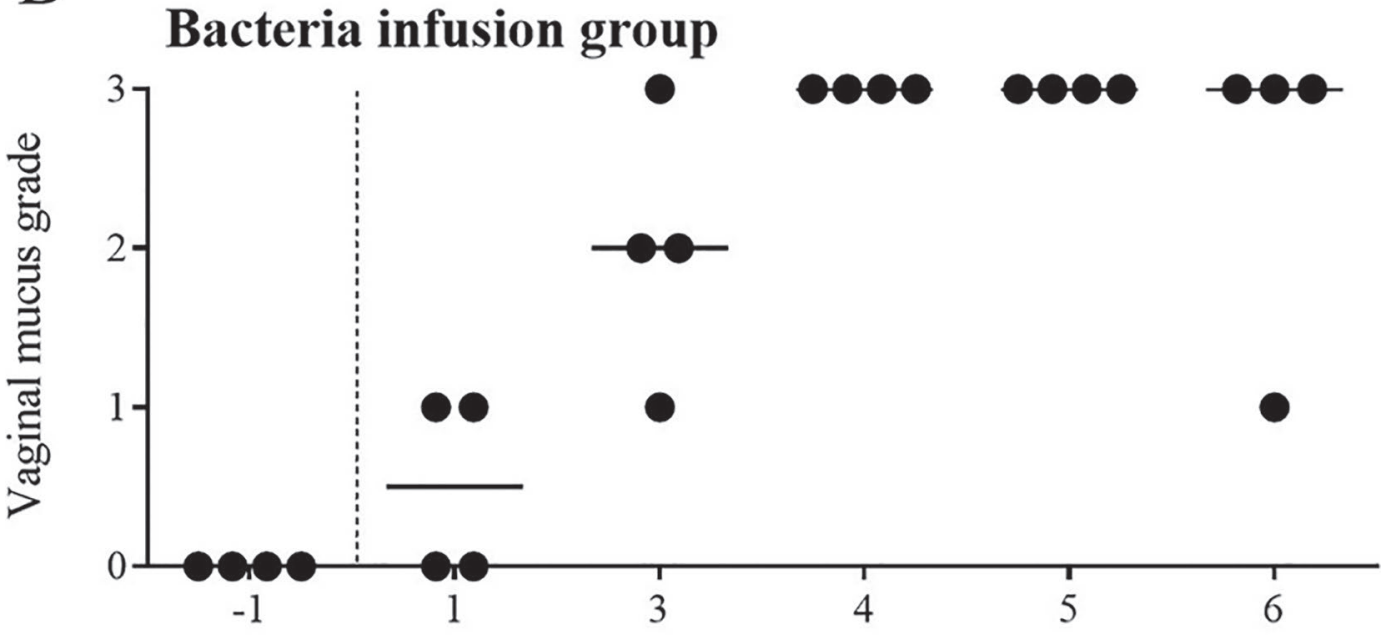

Days relative to treatment

Figure 3. Vaginal mucus grade following intrauterine infusion of bacteria. Vaginal mucus was collected using a Metricheck (Metricheck, Simcro, Hamilton, New Zealand) tool and graded according to Sheldon et al. (2009). Vaginal mucus was graded from 0 to 3 and each heifer is represented by a single circle. Control heifers are represented by open circles (A, $\mathrm{)}$ ), and bacteria-infused heifers are represented by filled circles $(\mathrm{B}, \mathbf{\bullet})$. The vertical dotted line denotes the day of treatment; solid horizontal lines indicate the median vaginal mucus score for the day of observation. Data were analyzed using the GLIMMIX procedure following a Poisson distribution to determine the effect of treatment (Trt). 

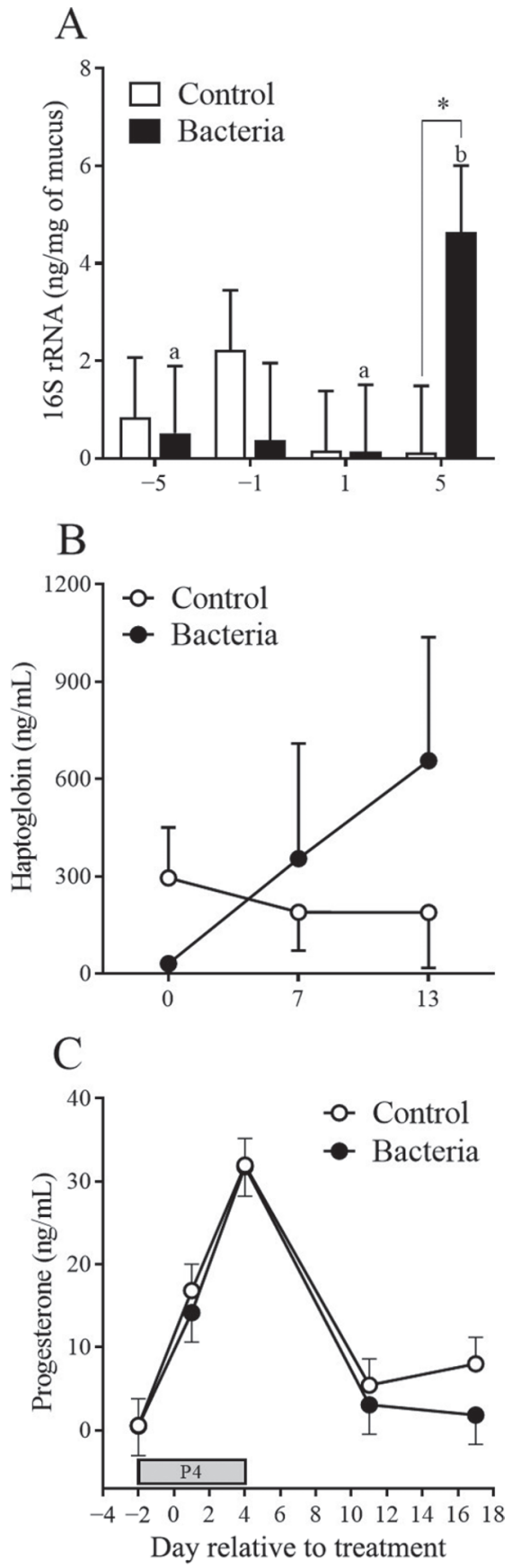

Figure 4. Effect of treatment on vaginal mucus $16 \mathrm{~S}$ rRNA and circulating concentrations of haptoglobin and progesterone in plasma. (A) Total $16 \mathrm{~S}$ rRNA quantification from vaginal mucus on $\mathrm{d}-5,-1$, 1 , and 5 relative to treatment in either control (open bars) or bacteriainfused (solid bars) heifers. Total $16 \mathrm{~S}$ rRNA was normalized to the weight of vaginal mucus processed for nucleic acid extraction (ng of rRNA per mg of mucus). Different letters denote differences within the bacteria-infused group; $*$ denotes difference between treatment groups on a given day $(P<0.05)$. (B) Haptoglobin plasma concentration (ng/ $\mathrm{mL}$ ) was measured in control $(O)$ and bacteria-infused $(\bullet)$ heifers on $\mathrm{d}$ 0,7 , and 13 relative to treatment. (C) Progesterone plasma concentration $(\mathrm{ng} / \mathrm{mL})$ was measured in control $(\mathrm{O})$ and bacteria-infused $(\bullet)$ heifers on $\mathrm{d}-2,1,4,11$, and 15 relative to treatment. Progesterone (P4) denotes the period of exogenous administration of $200 \mathrm{mg} / \mathrm{d}$ of $\mathrm{P} 4$. All data are presented as LSM \pm SEM.
Plasma concentrations of $\mathrm{P} 4$ increased in both treatment groups as a result of exogenous $\mathrm{P} 4$ supplementation (effect of day, $P<0.001$ ); however, infusion with bacteria did not affect concentrations of $\mathrm{P} 4$ in plasma $(P>0.05$, Figure $4 \mathrm{C})$. The peak concentration was observed on d 4 relative to treatment, and once exogenous P4 supplementation was concluded on d 4, concentrations decreased in both treatments.

\section{DISCUSSION}

The present experiment developed an in vivo model of clinical endometritis in Holstein heifers using pathogenic E. coli and T. pyogenes. Heifers that received intrauterine infusion of pathogenic bacteria developed purulent vaginal mucus, accumulation of echogenic fluid in the uterus, and increased bacterial load in vaginal mucus. In parallel, bacteria-infused heifers displayed no systemic signs of illness, such as altered hematology or general sickness. Control heifers did not display any of the clinical signs of clinical endometritis. Based on the criteria previously described for the disease, these results recapitulate the symptoms of clinical endometritis observed in the postpartum dairy cow (LeBlanc et al., 2002; Sheldon et al., 2006, 2009).

Previous experimental models of clinical endometritis have focused on the use of mature cows and intrauterine infusion of T. pyogenes (Rowson et al., 1953; Ayliffe and Noakes, 1982; Amos et al., 2014). These studies were capable of generating active infection of the uterus, evident by the presence of mucopurulent vaginal contents, using a single uterine pathogen. Although these models induce clinical symptoms of disease, it may be that the use of a second pathogen, $E$. coli, better reflects the molecular profile of endometritis to evaluate the consequences of disease on fertility. The dual pathogen model of Del Vecchio et al. (1992) used repeated infusions of both E. coli and T. pyogenes over the course of $3 \mathrm{~d}$ (Del Vecchio et al., 1992); however, the strain and pathogenicity of bacteria used may also be important. Strains used by others include $\beta$-hemolytic $E$. coli or T. pyogenes sourced from cows with severe endometritis (presumably from the uterus). Additionally, Farin et al. (1989) used intrauterine infusion of T. pyogenes and the gram-negative anaerobes, Fusobacterium necrophorum and Bacteroides melaninogenicus (now Prevotella melaninogenica), to induce "pyometria" in lactating multiparous cows. The model describes the implementation of tissue damage using an intrauterine infusion of iodine solution, and intravenous administration of hCG to ensure elevated circulating P4, 2 factors recapitulated in our model but using different approaches. The model of Farin et al. (1989) also reports the consistent isolation and culture of uterine $T$. 
Table 1. Effect of treatment on rectal temperature and hematology

\begin{tabular}{|c|c|c|c|c|c|c|c|}
\hline \multirow[b]{2}{*}{ Variable $^{1}$} & \multirow[b]{2}{*}{ Days $^{2}$} & \multicolumn{2}{|c|}{ Treatment } & \multirow[b]{2}{*}{ SEM } & \multicolumn{3}{|c|}{$P$-value ${ }^{3}$} \\
\hline & & Control & Bacteria & & Trt & Day & Trt $\times$ day \\
\hline \multirow[t]{4}{*}{ Temperature $\left({ }^{\circ} \mathrm{C}\right)$} & -1 & 38.4 & 38.3 & 0.1 & 0.08 & 0.01 & 0.19 \\
\hline & 1 & 38.7 & 39.5 & & & & \\
\hline & 3 & 38.3 & 38.7 & & & & \\
\hline & 7 & 38.5 & 38.5 & & & & \\
\hline \multirow[t]{4}{*}{$\mathrm{RBC}(\mathrm{M} / \mu \mathrm{L})$} & -1 & 6.78 & 6.36 & 0.31 & 0.3 & $<0.01$ & 0.85 \\
\hline & 1 & 7.79 & 7.03 & & & & \\
\hline & 3 & 7.37 & 6.75 & & & & \\
\hline & 7 & 7.17 & 6.70 & & & & \\
\hline \multirow[t]{4}{*}{$\mathrm{HCT}(\%)$} & -1 & 30.04 & 29.60 & 1.50 & 0.68 & $<0.01$ & 0.81 \\
\hline & 1 & 33.70 & 32.80 & & & & \\
\hline & 3 & 33.04 & 31.43 & & & & \\
\hline & 7 & 32.34 & 31.73 & & & & \\
\hline \multirow[t]{4}{*}{ HGB (g/dL) } & -1 & 10.20 & 9.93 & 0.52 & 0.65 & $<0.01$ & 0.96 \\
\hline & 1 & 11.24 & 10.98 & & & & \\
\hline & 3 & 11.00 & 10.55 & & & & \\
\hline & 7 & 10.80 & 10.43 & & & & \\
\hline \multirow[t]{4}{*}{$\mathrm{WBC}(\mathrm{K} / \mu \mathrm{L})$} & -1 & 12.12 & 11.72 & 0.85 & 0.65 & 0.45 & 0.86 \\
\hline & 1 & 12.31 & 12.81 & & & & \\
\hline & 3 & 10.38 & 11.43 & & & & \\
\hline & 7 & 10.96 & 12.08 & & & & \\
\hline \multirow[t]{4}{*}{ NEU (\%) } & -1 & 30.86 & 22.33 & 3.47 & 0.34 & 0.34 & 0.28 \\
\hline & 1 & 24.82 & 19.18 & & & & \\
\hline & 3 & 24.18 & 13.56 & & & & \\
\hline & 7 & 19.24 & 24.08 & & & & \\
\hline \multirow[t]{4}{*}{$\operatorname{NEU}(\mathrm{K} / \mu \mathrm{L})$} & -1 & 3.88 & 2.72 & 0.59 & 0.66 & 0.23 & 0.22 \\
\hline & 1 & 3.06 & 2.58 & & & & \\
\hline & 3 & 2.53 & 1.42 & & & & \\
\hline & 7 & 1.94 & 3.19 & & & & \\
\hline \multirow[t]{4}{*}{$\operatorname{LYM}(\%)$} & -1 & 44.24 & 54.38 & 4.64 & 0.70 & 0.27 & 0.11 \\
\hline & 1 & 50.12 & 58.35 & & & & \\
\hline & 3 & 50.98 & 51.23 & & & & \\
\hline & 7 & 60.80 & 52.70 & & & & \\
\hline \multirow[t]{4}{*}{$\mathrm{LYM}(\mathrm{K} / \mu \mathrm{L})$} & -1 & 5.20 & 6.25 & 0.43 & 0.29 & 0.59 & 0.51 \\
\hline & 1 & 6.14 & 7.35 & & & & \\
\hline & 3 & 5.33 & 6.64 & & & & \\
\hline & 7 & 6.89 & 6.07 & & & & \\
\hline \multirow[t]{4}{*}{ MON (\%) } & -1 & 17.44 & 16.95 & 1.88 & 0.52 & 0.27 & 0.37 \\
\hline & 1 & 18.32 & 14.93 & & & & \\
\hline & 3 & 18.00 & 26.60 & & & & \\
\hline & 7 & 14.32 & 17.18 & & & & \\
\hline \multirow[t]{4}{*}{$\operatorname{MON}(\mathrm{K} / \mu \mathrm{L})$} & -1 & 2.13 & 1.95 & 0.20 & 0.84 & 0.32 & 0.47 \\
\hline & 1 & 2.28 & 2.18 & & & & \\
\hline & 3 & 1.83 & 1.84 & & & & \\
\hline & 7 & 1.59 & 2.11 & & & & \\
\hline EOS (\%) & -1 & 7.42 & 6.30 & 1.00 & 0.86 & 0.13 & 0.27 \\
\hline & 1 & 6.68 & 5.50 & & & & \\
\hline & 3 & 6.80 & 9.18 & & & & \\
\hline & 7 & 5.01 & 6.03 & & & & \\
\hline $\operatorname{EOS}(\mathrm{K} / \mu \mathrm{L})$ & -1 & 0.91 & 0.80 & 0.15 & 0.85 & 0.14 & 0.20 \\
\hline & 1 & 0.81 & 0.69 & & & & \\
\hline & 3 & 0.70 & 0.92 & & & & \\
\hline & 7 & 0.53 & 0.72 & & & & \\
\hline $\operatorname{PLT}(\mathrm{K} / \mu \mathrm{L})$ & -1 & 312.2 & 241.00 & 68.98 & 0.45 & $<0.01$ & 0.82 \\
\hline & 1 & 380.00 & 261.00 & & & & \\
\hline & 3 & 318.20 & 221.00 & & & & \\
\hline & 7 & 146.20 & 117.75 & & & & \\
\hline
\end{tabular}

${ }^{1}$ Data are presented as LSM with respective pooled SEM for the interaction between treatment and day. Data quantified in whole blood included red blood cell count (RBC), hematocrit (HCT), hemoglobin concentration (HGB), white blood cell count (WBC), neutrophils (NEU), lymphocytes (LYM), monocytes (MON), eosinophils (EOS), and platelets (PLT) measured as the proportion of total cells (\%) and number of cells per $\mu \mathrm{L}(\mathrm{K}$ $=1,000 ; \mathrm{M}=1,000,000)$.

${ }^{2}$ Sample days relative to infusion ( $\mathrm{d}-1,1,3$, and 7$)$.

${ }^{3}$ Trt $=$ effect of treatment (control vs. bacteria); day $=$ effect of day relative to treatment; Trt $\times$ day $=$ interaction between Trt and day. 
pyogenes during an extended window of active disease lasting up to $30 \mathrm{~d}$ postinfusion in some cows. The presence of $E$. coli was not reported in these studies, and isolation and culture of the anaerobes, $F$. necrophorum and $P$. melaninogenica, were inconsistent between cows with disease (Farin et al., 1989). Pathogenic strains of E. coli and T. pyogenes used in the current model were sourced from the uterus of cows with endometritis and have subsequently been sequenced (Goldstone et al., 2014a,b), allowing a detailed understanding of virulence factors and host-pathogen interactions involved in disease. These 2 species of pathogens were specifically chosen to establish infection as they are readily detectable within days of parturition in the uterus of cows that develop spontaneous uterine disease (Dohmen et al., 2000; Bicalho et al., 2012). The pore-forming toxin produced by $T$. pyogenes causes cellular damage to the endometrium during active infection, although little is known about its actions on ovarian function, especially after the clearance of disease. Conversely, LPS derived from gram-negative bacteria is present in follicular fluid after the resolution of uterine disease. Indeed, studies have demonstrated that the presence of LPS negatively effects oocyte development and alters the follicular environment of the growing oocyte in vitro (Bromfield and Sheldon, 2011).

Species other than the cow have been used to develop models of uterine infection, including the sheep and mouse (Regassa et al., 2002; Sheldon and Roberts, 2010; Bromfield and Sheldon, 2013). However, when attempting to determine the mechanisms by which endometritis affects fertility of the dairy cow, it is imperative to use the target species in question. Rodents are relatively inexpensive and convenient for such a model, but the reproductive physiology and immune function of the mouse is considerably different from those of the cow. Mice have been shown to be 1 million-fold less sensitive to LPS than humans (Seok et al., 2013). More appropriately, the human and bovine genomes share a high degree of AA sequence homology, limited species-specific orthologs, and a similar chromosomal organization, suggesting the bovine as a useful experimental model for human physiology (The Bovine Genome Sequencing and Analysis Consortium et al., 2009). In addition, bovine reproductive biology is closer to that of humans than mice; cows and humans are both monotocous with similar hormonal profiles over a 3- to 4-wk ovarian cycle, compared with the polytocous mouse with a 4-d estrous cycle. The current model of endometritis may even serve as a tool to study the effects of uterine infections on human fertility.

The use of the Holstein heifers in the present experiment was a deliberate choice in the generation of the experimental model presented. The long-term goal of this model is to study the mechanisms of endometritismediated reproductive failure in the cow. As uterine disease occurs in the early postpartum period, several significant challenges can confound experimental investigation into the causes of endometritis-mediated infertility. Specifically, postpartum uterine damage, uterine involution, metabolic demands of lactation, negative nutrient balance, and additional postpartum illnesses that affect almost half of all postpartum cows (Ribeiro et al., 2016). Retained placenta and dystocia are significant risk factors for the development of endometritis, and are both associated with damage to the endometrium (Dubuc et al., 2010). To recapitulate postpartum endometrial damage, we performed a scarification procedure to disrupt the endometrial epithelial layer at the time of bacterial infusion. This process of scarification may be critical to the establishment of the disease model to facilitate bacterial access to the underlying stroma. Previous work has reported differential susceptibility of epithelial and stromal endometrial cells to pathogenic $E$. coli, with pathogenic E. coli binding with stronger affinity to stromal cells, and purified LPS inducing a stronger inflammatory reaction in the endometrial stroma (Sheldon et al., 2010). A similar phenomenon of differential cellular susceptibility has been described in the response of endometrial epithelial and stromal cells to $T$. pyogenes pyolysin, in which stroma cells are considerably more sensitive to the cytoxic effects of pyolysin (Amos et al., 2014), suggesting the stroma is the target of pyolysin. These in vitro experiments, in combination with the risk factors associated with endometritis, suggest that endometrial scarification may be an important procedure in the establishment of clinical endometritis observed in the present model.

The administration of exogenous $\mathrm{P} 4$ was a calculated approach to modulate the immune function of heifers at the time of bacterial infusion. Rowson et al. (1953) reported that intrauterine infusion of $T$. pyogenes (reported as Corynebacterium pyogenes) during the luteal phase of the estrous cycle resulted in "pyometritis"; however, no infection could be established when bacterial infusion was performed at estrus. These experiments were repeated using ovariectomized cows in conjunction with administration of exogenous P4 or estradiol. Only with the administration of exogenous P4 could pyometritis be achieved (Rowson et al., 1953). Since the $1950 \mathrm{~s}$, the immune modulating properties of $\mathrm{P} 4$ and estrogen have been reported in immune cells and the endometrium (reviewed in detail by Wira et al., 2015), with various studies demonstrating the immunesuppressive function of $\mathrm{P} 4$ within the endometrium of ruminants (Hawk et al., 1964; Del Vecchio et al., 1992; 
Hansen, 1998; Seals et al., 2002; Lewis, 2003). The ability of steroid hormones to modulate endometrial immune function have led to the practice of administering $\mathrm{PGF}_{2 \alpha}$ as a treatment for uterine infection to induce luteolysis in cows in diestrus, and elevate estrogen by stimulating a new follicular phase of the estrous cycle (Lewis, 1997); however, this remains debated. In parallel, $55 \%$ of cows with metritis display extended luteal phases (Etherington et al., 1991; Opsomer et al., 2000). The extension of the luteal phase in cows with uterine disease can have consequences on the calving to conception interval, negatively affecting productivity. Exposure of endometrial cells to bacterial LPS in vitro switches prostaglandin synthesis from luteolytic $\mathrm{PGF}_{2 \alpha}$ to luteotrophic $\mathrm{PGE}_{2}$ (Herath et al., 2006, 2009). This apparent LPS-mediated switch in endometrial secretion of luteotrophic $\mathrm{PGE}_{2}$ may explain the extended luteal phase in some cows with uterine disease. In the current study we evaluated circulating P4 until d 18 postinfusion, and did not observe any effect of treatment at any time point. This result may be an influence of exogenous $\mathrm{P} 4$ administration for 7 consecutive days, or an artifact of the extensive manual manipulations performed on these heifers during the course of the study. Future studies using this model of induced infection should evaluate the duration of the luteal phase, monitoring follicular growth, ovulation, CL size, peak $\mathrm{P} 4$, and luteal phase duration.

Vaginal mucopurulent content observed in heifers treated with intrauterine infusion containing live bacteria could be associated with cervicitis or vaginitis as previously observed in spontaneously occurring cases in postpartum cows (Dubuc et al., 2010). Although the infusate was placed in the uterine horns, retrograde movement of the content could have inoculated the cervix and vagina. However, quantification of vaginal $16 \mathrm{~S}$ rRNA the day after infusion on experiment $\mathrm{d} 1$ revealed comparable total bacterial load between treatments. The presence of elevated 16S rRNA observed in the bacteria-infused heifers $5 \mathrm{~d}$ following infusion suggests that mucopurulent vaginal discharge is derived from the infected uterus induced by infused bacteria, and not from environmental contamination. The accumulation of echogenic uterine fluid in bacteria-infused heifers supports these assumptions and suggests that any cervicitis or vaginitis would likely be the result of contamination or excessive manipulation, and would also be observed in vehicle-infused controls. Interestingly, however, hematological evaluation of heifers suggests a possible effect of the procedure of infusing material into the uterus itself. Although we did not observe a treatment effect for any of the hematological parameters evaluated, we did see an effect of day on numbers of red blood cells, lymphocytes, and platelets, and the percent of hematocrit and hemoglobin. Consistently, all of these parameters were elevated $24 \mathrm{~h}$ following infusion and steadily declined to pre-infusion levels by $\mathrm{d} 7$. This observation may be indicative of the manual manipulation affecting systemic hematological parameters in the heifers.

Any experimental model of infection has limitations. Here, we propose using the described experimental model to define the mechanisms of endometritis-mediated subfertility. However, using heifers as the experimental unit limits our understanding of the reproductive potential of the individual animal, unlike using mature lactating cows that would normally have uterine disease. Additionally, the use of heifers revealed experimental limitations because of body size and ability to perform the manipulations in 12- to 13-mo-old animals, indicated by the consistent day effect of some hematological parameters. Experimentation for the purposes of determining mechanisms of endometritis-mediated subfertility will require multiple, repeat manipulations that might be difficult in small-frame heifers compared with mature cows. The longevity of the experimental model is also an important factor to determine in future cohorts of animals; it will be important to establish that the infection observed in the current cohort of heifers is reminiscent of the duration of spontaneous endometritis observed in lactating cows. Additionally, quantification of endometrial inflammation and microbial populations present as a result of experimentally induced infection will be critical to establish the validity of the model to study endometritis-mediated subfertility in the dairy cow.

\section{CONCLUSIONS}

We have successfully created a model of experimentally induced clinical endometritis in virgin Holstein heifers. This model will allow the investigation into the mechanisms of endometritis-associated reproductive failure. The use of an experimental model of endometritis allows investigation into endometritis-mediated subfertility independent of confounding postpartum events common in lactating cows that may influence reproductive physiology. We used a combination of interventions to facilitate uterine infection, including disruption of the endometrial epithelial barrier, supplementation of exogenous $\mathrm{P} 4$, and infusion of uterine pathogenic bacteria. We conclude that our experimental model recapitulates clinical endometritis symptoms in virgin Holstein heifers. 


\section{ACKNOWLEDGMENTS}

The authors thank Todd Pritchard, Miguel Torrado, and the University of Florida Dairy Research Unit staff for their assistance. Research reported in this publication was supported by the Eunice Kennedy Shriver National Institute of Child Health \& Human Development of the National Institutes of Health (Bethesda, MD) under Award Number R01HD084316. The content is solely the responsibility of the authors and does not necessarily represent the official views of the National Institutes of Health.

\section{REFERENCES}

Amos, M. R., G. D. Healey, R. J. Goldstone, S. M. Mahan, A. Duvel, H. J. Schuberth, O. Sandra, P. Zieger, I. Dieuzy-Labaye, D. G. Smith, and I. M. Sheldon. 2014. Differential endometrial cell sensitivity to a cholesterol-dependent cytolysin links Trueperella pyogenes to uterine disease in cattle. Biol. Reprod. 90:54.

Ayliffe, T. R., and D. E. Noakes. 1982. Effects of exogenous oestrogen and experimentally induced endometritis on absorption of sodium benzylpenicillin from the cow's uterus. Vet. Rec. 110:96-98.

Bicalho, M. L., V. S. Machado, G. Oikonomou, R. O. Gilbert, and R. C. Bicalho. 2012. Association between virulence factors of Escherichia coli, Fusobacterium necrophorum, and Arcanobacterium pyogenes and uterine diseases of dairy cows. Vet. Microbiol. 157:125-131.

Bromfield, J. J., and I. M. Sheldon. 2011. Lipopolysaccharide initiates inflammation in bovine granulosa cells via the TLR4 pathway and perturbs oocyte meiotic progression in vitro. Endocrinology 152:5029-5040.

Bromfield, J. J., and I. M. Sheldon. 2013. Lipopolysaccharide reduces the primordial follicle pool in the bovine ovarian cortex ex vivo and in the murine ovary in vivo. Biol. Reprod. 88:98.

The Bovine Genome Sequencing and Analysis Consortium, C. G. Elsik, R. L. Tellam, and K. C. Worley. 2009. The genome sequence of taurine cattle: A window to ruminant biology and evolution. Science 324:522-528.

Chagas, L. M., J. J. Bass, D. Blache, C. R. Burke, J. K. Kay, D. R. Lindsay, M. C. Lucy, G. B. Martin, S. Meier, F. M. Rhodes, J. R. Roche, W. W. Thatcher, and R. Webb. 2007. Invited review: New perspectives on the roles of nutrition and metabolic priorities in the subfertility of high-producing dairy cows. J. Dairy Sci. 90:4022-4032.

Del Vecchio, R. P., D. J. Matsas, T. J. Inzana, D. P. Sponenberg, and G. S. Lewis. 1992. Effect of intrauterine bacterial infusions and subsequent endometritis on prostaglandin F2 alpha metabolite concentrations in postpartum beef cows. J. Anim. Sci. 70:31583162 .

Dohmen, M. J., K. Joop, A. Sturk, P. E. Bols, and J. A. Lohuis. 2000. Relationship between intra-uterine bacterial contamination, endotoxin levels and the development of endometritis in postpartum cows with dystocia or retained placenta. Theriogenology 54:1019 1032.

Dubuc, J., T. F. Duffield, K. E. Leslie, J. S. Walton, and S. J. LeBlanc. 2010. Risk factors for postpartum uterine diseases in dairy cows. J. Dairy Sci. 93:5764-5771.

Etherington, W. G., K. A. Christie, J. S. Walton, K. E. Leslie, S. Wickstrom, and W. H. Johnson. 1991. Progesterone profiles in postpartum Holstein dairy cows as an aid in the study of retained fetal membranes, pyometra and anestrus. Theriogenology 35:731746.

Farin, P. W., L. Ball, J. D. Olson, R. G. Mortimer, R. L. Jones, W. S. Adney, and A. E. McChesney. 1989. Effect of Actinomyces pyo- genes and gram-negative anaerobic bacteria on the development of bovine pyometra. Theriogenology 31:979-989.

Gernand, E., P. Rehbein, U. U. von Borstel, and S. Konig. 2012. Incidences of and genetic parameters for mastitis, claw disorders, and common health traits recorded in dairy cattle contract herds. J. Dairy Sci. 95:2144-2156.

Goldstone, R. J., M. Amos, R. Talbot, H. J. Schuberth, O. Sandra, I. M. Sheldon, and D. G. Smith. 2014a. Draft genome sequence of Trueperella pyogenes, isolated from the infected uterus of a postpartum cow with metritis. Genome Announc. 2:e00194-e00214.

Goldstone, R. J., R. Talbot, H. J. Schuberth, O. Sandra, I. M. Sheldon, and D. G. Smith. 2014b. Draft genome sequence of Escherichia coli MS499, isolated from the infected uterus of a postpartum cow with metritis. Genome Announc. 2:e00217-e00314.

Hansen, P. J. 1998. Regulation of uterine immune function by progesterone-Lessons from the sheep. J. Reprod. Immunol. 40:63-79.

Hawk, H. W., T. H. Brinsfield, G. D. Turner, G. W. Whitmore, and M. A. Norcross. 1964. Effect of ovarian status on induced acute inflammatory responses in cattle uteri. Am. J. Vet. Res. 25:362-366.

Herath, S., D. P. Fischer, D. Werling, E. J. Williams, S. T. Lilly, H. Dobson, C. E. Bryant, and I. M. Sheldon. 2006. Expression and function of Toll-like receptor 4 in the endometrial cells of the uterus. Endocrinology 147:562-570.

Herath, S., S. T. Lilly, D. P. Fischer, E. J. Williams, H. Dobson, C. E. Bryant, and I. M. Sheldon. 2009. Bacterial lipopolysaccharide induces an endocrine switch from prostaglandin F2alpha to prostaglandin E2 in bovine endometrium. Endocrinology 150:1912-1920.

LeBlanc, S. J. 2012. Interactions of metabolism, inflammation, and reproductive tract health in the postpartum period in dairy cattle. Reprod. Domest. Anim. 47(Suppl 5):18-30.

LeBlanc, S. J., T. F. Duffield, K. E. Leslie, K. G. Bateman, G. P. Keefe, J. S. Walton, and W. H. Johnson. 2002. Defining and diagnosing postpartum clinical endometritis and its impact on reproductive performance in dairy cows. J. Dairy Sci. 85:2223-2236.

Lewis, G. S. 1997. Uterine health and disorders. J. Dairy Sci. 80:984994.

Lewis, G. S. 2003. Role of ovarian progesterone and potential role of prostaglandin F2alpha and prostaglandin E2 in modulating the uterine response to infectious bacteria in postpartum ewes. J. Anim. Sci. 81:285-293.

Lima, F. S., E. S. Ribeiro, R. S. Bisinotto, L. F. Greco, N. Martinez M. Amstalden, W. W. Thatcher, and J. E. Santos. 2013. Hormonal manipulations in the 5-day timed artificial insemination protocol to optimize estrous cycle synchrony and fertility in dairy heifers. J. Dairy Sci. 96:7054-7065.

Opsomer, G., Y. T. Grohn, J. Hertl, M. Coryn, H. Deluyker, and A. de Kruif. 2000. Risk factors for post partum ovarian dysfunction in high producing dairy cows in Belgium: A field study. Theriogenology $53: 841-857$.

Potter, T. J., J. Guitian, J. Fishwick, P. J. Gordon, and I. M. Sheldon. 2010. Risk factors for clinical endometritis in postpartum dairy cattle. Theriogenology 74:127-134.

Regassa, F., M. Sheldon, and D. E. Noakes. 2002. Effect of experimentally induced metritis on uterine involution, acute phase protein response and PGFM secretion in the postpartum ewe. Vet. Rec. 150:605-607.

Ribeiro, E. S., G. Gomes, L. F. Greco, R. L. A. Cerri, A. Vieira-Neto, P. L. J. Monteiro Jr., F. S. Lima, R. S. Bisinotto, W. W. Thatcher, and J. E. P. Santos. 2016. Carryover effect of postpartum inflammatory diseases on developmental biology and fertility in lactating dairy cows. J. Dairy Sci. 99:2201-2220.

Ribeiro, E. S., F. S. Lima, L. F. Greco, R. S. Bisinotto, A. P. Monteiro, M. Favoreto, H. Ayres, R. S. Marsola, N. Martinez, W. W. Thatcher, and J. E. Santos. 2013. Prevalence of periparturient diseases and effects on fertility of seasonally calving grazing dairy cows supplemented with concentrates. J. Dairy Sci. 96:5682-5697.

Rowson, L. E., G. E. Lamming, and R. M. Fry. 1953. Influence of ovarian hormones on uterine infection. Nature 171:749-750. 
Seals, R. C., M. C. Wulster-Radcliffe, and G. S. Lewis. 2002. Modulation of the uterine response to infectious bacteria in postpartum ewes. Am. J. Reprod. Immunol. 47:57-63.

Seok, J., H. S. Warren, A. G. Cuenca, M. N. Mindrinos, H. V. Baker, W. Xu, D. R. Richards, G. P. McDonald-Smith, H. Gao, L. Hennessy, C. C. Finnerty, C. M. Lopez, S. Honari, E. E. Moore, J. P. Minei, J. Cuschieri, P. E. Bankey, J. L. Johnson, J. Sperry, A. B. Nathens, T. R. Billiar, M. A. West, M. G. Jeschke, M. B. Klein, R. L. Gamelli, N. S. Gibran, B. H. Brownstein, C. Miller-Graziano, S. E. Calvano, P. H. Mason, J. P. Cobb, L. G. Rahme, S. F. Lowry, R. V. Maier, L. L. Moldawer, D. N. Herndon, R. W. Davis, W. Xiao, and R. G. Tompkins. Inflammation and Host Response to Injury, and Large Scale Collaborative Research Program. 2013. Genomic responses in mouse models poorly mimic human inflammatory diseases. Proc. Natl. Acad. Sci. USA 110:3507-3512.

Sheldon, I. M., J. Cronin, L. Goetze, G. Donofrio, and H. J. Schuberth. 2009. Defining postpartum uterine disease and the mechanisms of infection and immunity in the female reproductive tract in cattle. Biol. Reprod. 81:1025-1032.

Sheldon, I. M., G. S. Lewis, S. LeBlanc, and R. O. Gilbert. 2006 Defining postpartum uterine disease in cattle. Theriogenology 65:1516-1530.

Sheldon, I. M., D. E. Noakes, A. Rycroft, and H. Dobson. 2001. Acute phase protein responses to uterine bacterial contamination in cattle after calving. Vet. Rec. 148:172-175.
Sheldon, I. M., D. E. Noakes, A. N. Rycroft, D. U. Pfeiffer, and H. Dobson. 2002. Influence of uterine bacterial contamination after parturition on ovarian dominant follicle selection and follicle growth and function in cattle. Reproduction 123:837-845.

Sheldon, I. M., and M. H. Roberts. 2010. Toll-like receptor 4 mediates the response of epithelial and stromal cells to lipopolysaccharide in the endometrium. PLoS One 5:e12906.

Sheldon, I. M., A. N. Rycroft, B. Dogan, M. Craven, J. J. Bromfield, A. Chandler, M. H. Roberts, S. B. Price, R. O. Gilbert, and K. W. Simpson. 2010. Specific strains of Escherichia coli are pathogenic for the endometrium of cattle and cause pelvic inflammatory disease in cattle and mice. PLoS One 5:e9192.

Turner, M. L., J. G. Cronin, G. D. Healey, and I. M. Sheldon. 2014 Epithelial and stromal cells of bovine endometrium have roles in innate immunity and initiate inflammatory responses to bacterial lipopeptides in vitro via Toll-like receptors TLR2, TLR1, and TLR6. Endocrinology 155:1453-1465.

Wira, C. R., M. Rodriguez-Garcia, and M. V. Patel. 2015. The role of sex hormones in immune protection of the female reproductive tract. Nat. Rev. Immunol. 15:217-230. 